\title{
The effect of bone marrow mesenchymal stem cells on highly metastatic MHCC97-H hepatocellular carcinoma cells following OPN and TGFß1 gene silencing
}

\author{
BEIBEI ZHANG*, LIUTONG SHANG, YI ZHANG*, TIANRAN LI and YUAN FANG \\ Department of Radiology, the Fourth Medical Center of Chinese PLA General Hospital, Beijing 100048, P.R. China
}

Received October 9, 2019; Accepted June 10, 2020

DOI: $10.3892 / \mathrm{etm} .2020 .9106$

\begin{abstract}
The metastatic behavior of hepatocellular carcinoma (HCC) is one of the key factors that leads to poor prognosis. The aim of the current study was to determine the changes in metastasis and the proliferation potential of bone marrow mesenchymal stem cells (BMSCs) in high metastatic potential hepatocellular carcinoma (MHCC97-H) following genesilencing. The osteopontin $(O P N)$ and transforming growth factor- $\beta\left(T G F \beta_{l}\right)$ genes, which are associated with metastasis and tumor proliferation, were silenced in MHCC97-H cells. Transwell assays were used to evaluate the migration of MHCC97-H cells in vitro. Additionally, a murine model of MHCC97-H lung metastasis was established. Following OPN and $T G F \beta_{1}$ silencing, the migration of MHCC97-H cells was significantly reduced following BMSC intervention $(\mathrm{P}<0.01)$. Furthermore, there were few MHCC97-H cells in the lung tissues of the $O P N$ - and $T G F \beta_{1}$-silenced animals, and their integrated optical density (IOD) value was significantly lower compared with controls $(\mathrm{P}<0.05)$. Immunofluorescence of lung metastasis in the MHCC97-H model revealed that there was no significant difference in the IOD value of integrin $\alpha_{v} \beta_{3}$ expression in the $O P N$ - and $T G F \beta_{1}$-silenced groups compared with controls $(\mathrm{P}>0.05)$. The metastasis and proliferation potential of MHCC97-H following BMSC intervention were significantly reduced in vitro and in vivo, especially in the TGF $\beta_{1}$-silenced group. The decrease in the metastatic potential
\end{abstract}

Correspondence to: Dr Tianran Li, Department of Radiology, the Fourth Medical Center of Chinese PLA General Hospital, 51 Fucheng Road, Haidian, Beijing 100048, P.R. China

E-mail: 1tranmd@yeah.net

${ }^{*}$ Contributed equally

Abbreviations: BMSCs, bone marrow-derived mesenchymal stem cells; HCC, hepatocellular carcinoma; MHCC97-H, high metastatic potential hepatocellular carcinoma; OPN, osteopontin; TGF $\beta 1$, transforming growth factor- $\beta$; IOD, integrated optical density

Key words: hepatocellular carcinoma, BMSCs, metastasis, OPN, transforming growth factor, integrin in gene-silenced MHCC97-H cells was not associated with integrin $\alpha_{\mathrm{v}} \beta_{3}$ expression. Therefore, OPN and TGF $\beta_{1}$ may be potential targets for HCC treatment, and $\mathrm{TGF} \beta_{1}$ may have a higher therapeutic potential for BMSC intervention.

\section{Introduction}

In China, hepatocellular carcinoma (HCC) is a common, malignant tumor with poor prognosis (1). The mortality rate of HCC is the 3rd highest among all malignant tumors (1). Metastasis and recurrence are the main causes of poor prognosis (2). The invasion and metastasis of HCC is a complex multi-gene, multi-step and multi-factor process involving interactions between cancer cells, and between cancer cells and the host microenvironment (3). As multiple biological factors are involved in HCC metastasis, HCC models with different metastatic potentials constructed by the Hepatocellular Carcinoma Institute of Fudan University have become an effective means to study the metastatic behavior of HCC (4). For example, the highly metastatic HCC cell line MHCC97-H has a lung metastasis rate of $100 \%$ (5). Therefore, this cell line is the most effective model for studying HCC lung metastasis (6).

The development of stem cell technology has provided novel data for the occurrence, progress and treatment of HCC. Stem cell technology can be divided into normal stem cell technology and cancer stem cell (CSC) technology. The CSC concept states that tumor growth, analogous to the renewal of healthy tissues, is fueled by small numbers of dedicated stem cells (7). Normal stem cell technology refers to the use of human normal stem cells for tumor intervention techniques in order to observe their role on tumors or tumor cells (8). Autologous bone marrow mesenchymal stem cells (BMSCs) transplantation is a promising tool for tumor treatment (9). In liver disease, for example liver cirrhosis, autologous BMSCs generate hepatocytes and bile duct cells, which can repair damaged liver tissue and therefore prevent liver transplantation (10). This method has become the point of focus in research for HCC biotherapy due to its advantages, including easy collection, ability to avoid rejection reactions, simple and easy transplantation process, low treatment cost and absence of ethical concerns $(11,12)$.

Current research focuses mainly on the biological intervention of BMSCs for the metastatic potential of HCC, which provides a basis for finding suitable biotherapeutic 
targets $(13,14)$. However, there are still numerous uncertainties regarding the efficacy of BMSCs in tumor intervention, including stem cell tumorigenicity, long term interventional efficacy and the influence of stem cells on the biological behavior of tumors, which all require further research and observation (8).

In a previous study, autologous BMSCs were genetically modified to upregulate osteopontin $(O P N)$ and transforming growth factor $\beta_{1}\left(T G F \beta_{l}\right)$ gene expression in order to observe the effect of stem cells on HCC cells with high (MHCC97-H) and low (MHCC97-L) metastatic potentials. OPN promotes tumor metastasis following interaction with integrin $\alpha v \beta 3$ and induces cell movement by altering the cytoskeleton, promoting angiogenesis and cell adhesion, and preventing cell apoptosis (15). Exogenous OPN secretion by BMSCs serves a role in promoting tumor invasion by inhibiting the secretion of endogenous OPN in MHCC97-H cells, mainly by activating matrix metalloproteinase-2 (15). Previous studies have also demonstrated that $\mathrm{TGF} \beta_{1}$ is associated with tumor proliferation and has different effects on liver cancer cells with high and low metastatic potentials (16), namely, the ability of BMSCs with TGF $\beta_{1}$ to promote MHCC97-L invasion was higher than that for MHCC97-H (17) and MSCs may be capable of enhancing the angiogenesis of HCC, which may be partly due to the involvement of TGF $\beta 1$ (18). In the relationship between TGF $\beta 1$, OPN and integrin $\alpha_{v} \beta_{3}$, OPN mediates the adhesion of integrin to the extracellular matrix (ECM) and becomes a critical factor in tumor metastasis, while TGF $\beta_{1}$ activates protein kinase $\mathrm{B}$ by regulating the expression of integrin linked kinase. TGF $\beta_{1}$ promotes the phosphorylation of focal adhesion kinase tyrosine and activates downstream signaling molecules to directly or indirectly participate in the adhesion of integrin and ECM, which promotes HCC invasion and metastasis $(19,20)$.

Based on previous findings, the current study was designed to determine the effect of reduced OPN and TGF $\beta_{1}$ levels on MHCC 97-H metastasis. Therefore, the metastasis-associated gene $O P N$ and the tumor growth-related gene $T G F \beta_{1}$ were silenced using small interfering RNAs (siRNAs) in MHCC97-H cells and the change in metastatic potential was evaluated. Furthermore, the effect of BMSCs on MHCC97-H following gene silencing was also evaluated.

\section{Materials and methods}

Instruments and reagents. Instruments used included: a frozen microtome (HM525 NX; Thermo Fisher Scientific, Inc.), an upright fluorescence microscope (BX43; Olympus Corporation), a refrigerator (BCD-211KD3; TCL Corporation), a rotary microtome (RM2235; Leica Microsystems $\mathrm{GmbH}$ ), a pathological tissue drift Bakeware (Tec 2500; Changzhou Haosilin Instrument Equipment Co., Ltd.), a rotary table scanning confocal microscope (DSU; Olympus Corporation), an electric thermostatic blast drying oven (101-3, Shanghai Jinping Instrument Co., Ltd.), a water-proof constant temperature incubator (PYX-DHS500BS-II; Shanghai Yuejin Medical Devices Co., Ltd.), an electronic balance (FA1104; Shanghai Tianping Instrument Factory), an ultra-low temperature refrigerator (BS-812; Qingdao Haier Co., Ltd.) and a purification bench (SW-CJ-2D; Shanghai Xinmiao Medical Instrument Manufacturing Co., Ltd.).
Reagents used included: mouse polyclonal integrin $\alpha_{v} \beta_{3}$ antibody (L2206; Santa Cruz Animal Health; 1:50), donkey anti-rabbit fluorescent secondary antibody (15316; Thermo Fisher Scientific, Inc.; 1:800; excitation/emission wavelength: 490/520 nm); citric acid antigen recovery solution ( $\mathrm{pH} \mathrm{6.0;}$ Fuzhou Maixin Biotechnology Co., Ltd.), xylene (Chengdu Kelong Chemical Reagent Factory), anhydrous ethanol (Chengdu Kelong Chemical Reagent Factory) and DAPI (Sigma-Aldrich; Merck KGaA; absorption wavelength/emission wavelength: 358/461 nm). DMEM medium, trypsin and $0.02 \%$ EDTA were purchased from Gibco, Thermo Fisher Scientific, Inc. Phosphate buffered saline (PBS) was purchased from China Pharmaceutical Chemicals Co., Ltd. Fetal bovine serum (FBS) was purchased from Biological Industries, blue streptomycin (100 x double antibody) from Hangzhou Haotian Biotechnology Co., Ltd., and L-Glutamine medium from Shanghai Ruibosai Biological Technology Co., Ltd.

Cell experiment and culture methods. MHCC97-H were provided by the Institute of Liver Cancer at Fudan University. MHCC97-H cells were incubated with $10 \%$ FBS with $1 \mathrm{X}$ DMEM medium at $37^{\circ} \mathrm{C}$ in a $5 \% \mathrm{CO}_{2}$ incubator. Cells were subcultured by washing with PBS, followed by dissociation with $0.25 \%$ trypsin and $0.02 \%$ EDTA. BMSCs were provided by Saiye Biotechnology Co., Ltd., (cat. no. HUXMA-90011). BMSCs were derived from the bone marrow of healthy adults (18-45 years), purchased from Saiye Biotechnology Co., Ltd., (cat. no. HUXMA-90011). BMSCs were cultured and passaged to the 2nd generation in vitro and then stored frozen. BMSCs activity was tested before each experiment, include BMSCs growth state, differentiation ability and cluster differentiation tests. BMSCs were incubated with $10 \%$ FBS (Gibco; Thermo Fisher Scientific, Inc.) + 1X MSCM (Beijing Yuhengfeng Technology Co., Ltd.) + L-Glutamine medium at $37^{\circ} \mathrm{C}$ in a $5 \% \mathrm{CO}_{2}$ incubator. When cells confluence reached $90 \%$, BMSCs were passaged by washing with PBS, followed by dissociation with $0.25 \%$ Trypsin and $0.02 \%$ EDTA.

Animal experiments and feeding conditions. Animal experiments were approved by the Ethics Committee of the Fourth Medical Center of the Chinese PLA General Hospital. A total of 32 male BALB/c nude mice, aged 4-5 weeks, were provided by Shanghai SLAC Experimental Animal Co., Ltd. The production license no. was SCXK 2012-0002, SPF grade and the animal quality certification no. was 0205939 . At the time of purchase, each animal weighed $20 \pm 2 \mathrm{~g}$. Sterilized ultrapure drinking water was provided to the mice and the quality of drinking water met the provisions of the People's Republic of China National Standard for Drinking Water Hygiene (GB5749-2006). The animal maintenance feed was provided by Shanghai SLAC Experimental Animals Co., Ltd., and the standard GB14924.3-2010 'Nutrient Components of Compound Feeds for Experimental Animals' protocol was implemented (21). The laboratory animal room use permit no. was SYXK 2015-0008. The mice were housed at temperatures of $20-25^{\circ} \mathrm{C}$ and the relative humidity range was $40-70 \%$. Animal lighting 10-20 Lux, light and dark cycle 10/14 h, work lighting 100-200 Lux. Nude mice were adapted for 6 days in the animal room environment before testing. Following animal experiments, the tumor-bearing animals were euthanized. 
MHCC97-H gene silencing.Previous results have demonstrated that $\mathrm{MHCC} 97-\mathrm{H}$ overexpresses the metastasis-associated gene $O P N$ and the proliferation-related gene $T G F \beta_{l}$ (5). Therefore, the current study separately interfered with these genes.

Construction of adenoviral vectors: $T G F \beta_{1}$ siRNA1 sequence (GTGGAGCTGTACCAGAAAT) and $O P N$ siRNA1 sequence (GAGGAGTTGAATGGTGCATAC) were used to synthesize oligo sequences purified from a PAGE gel, and gene sequences obtained from GeneBank (http://ncbi.nlm. nih.gov/GenBank/). Vectors were digested with BamH I and EcoR I (New England Biolabs, Inc.) and recovered by cutting. Following annealing at $50^{\circ} \mathrm{C}$ for $30 \mathrm{sec}$, single strands of short hairpin RNA (shRNA) $3^{\prime}$ and $5^{\prime}$ fragments were obtained. The shRNA of the target fragment was ligated with the vector and transformed into TGF $\beta_{1}$.The oligonucleotide fragment was diluted 100 times with water for use, and Annealing Buffer (Beijing Solarbio Science and Technology Co., Ltd.) for Oligos (5x) was added. Annealing was performed at $95^{\circ} \mathrm{C}$ for $5 \mathrm{~min}$, then naturally cooled to room temperature. The ligation reaction solution was as follows: T4 DNA ligase $5 \mathrm{U}$, linearized carrier $2 \mu \mathrm{l}$, diluted oligonucleotide $2 \mu \mathrm{l}$ and 10X ligase buffer $1 \mu \mathrm{l}$, made up to $10 \mu \mathrm{l}$ with water. Consecutive reactions were performed according to the manufacturer's instructions.

Recombinant adenovirus TGF $\beta_{1}$ and $O P N$ shRNA adenoviruses. Recombinant plasmids were prepared and packaged with recombinant adenoviral vectors. The Lentivirus was collected and amplified in $\sim 10^{7}$ cells at an inoculating cell density of $2-5 \times 10^{4} 293 \mathrm{~T}$ cells $/ \mathrm{cm}^{2}$ in a $75 \mathrm{~cm}^{2}$ square bottle containing DMEM $+10 \%$ FBS. A total of $10 \mathrm{ml}$ of the virus supernatant was added to infect the cells. After 3-4 days, the cells almost became round and half of the cells were in suspension. At this point, all of the cells were collected and centrifuged at $500 \mathrm{x} \mathrm{g}, 37^{\circ} \mathrm{C}$ for $60 \mathrm{~min}$ and the supernatant was discarded. $T G F \beta_{1}$ and $O P N$ shRNA adenovirus assays were performed and Green Fluorescent protein (GFP; Abcam) was used as a marker gene. PCR was used to identify recombinant viruses. A total of $5 \mu \mathrm{l}$ virus supernatant was taken and $10 \mu \mathrm{l}$ proteinase $\mathrm{K}$ was added, incubated at $55^{\circ} \mathrm{C}$ for $1 \mathrm{~h}$, then boiled for $5 \mathrm{~min}$. After a further centrifugation at $4000 \mathrm{x} \mathrm{g}$, $37^{\circ} \mathrm{C}, 5 \mathrm{~min}, 1-2 \mu 1$ was used for PCR. The virus was then used to infect MHCC97-H cells. GFP was used as the marker gene. Expression levels of TGF $\beta_{1}$ and OPN in MHCC97-H cells were measured before and after gene interference using reverse transcription quantitative (RT-q)PCR. RT-qPCR was performed using homo $O P N$ forward, AGGAGGAGGCAGAGCACA and reverse, CTGGTATGGCACAGGTGATG; and homo $T G F \beta 1$ forward, GGCGATACCTCAGCAACCG and reverse, CTAAGGCGAAAGCCCTCAAT. A total of $1 \times 10^{6}$ MHCC97-H cells were collected, lysed and centrifuged $\left(4^{\circ} \mathrm{C}, 12,000 \mathrm{x} \mathrm{g}, 20 \mathrm{~min}\right)$ using a $\mathrm{TRIzol}^{\circledR}$-spin column (Invitrogen; Thermo Fisher Scientific, Inc.). RNA purity was verified by placing $2 \mu \mathrm{l}$ of RNA solution on the Micro-volume Spectrophotometer SMA4000 (Merinton Instrument, Inc.). RNA was reverse transcribed to cDNA using a High-Capacity RNA-to-cDNA ${ }^{\mathrm{TM}}$ kit (Invitrogen; Thermo Fisher Scientific, Inc.) according to operating instructions. $\beta$-actin was used as the internal control. The PCR reaction conditions were: $93^{\circ} \mathrm{C}$ for $2 \mathrm{~min}$, then $93^{\circ} \mathrm{C}$ for $1 \mathrm{~min}$, and $55^{\circ} \mathrm{C}$ for $2 \mathrm{~min}$, for a total of 40 cycles. The blank control group of $O P N$ and $T G F \beta 1$ were used as the relative quantitative PCR expression levels and were normalized by the internal control (22). Relative expression levels were calculated using the $2^{-\Delta \Delta \mathrm{Cq}}$ method.

MHCC97-H cell and BMSCs co-culture migration experiment. The Transwell method was used to evaluate the metastatic ability at the cellular level, as it simulates the basement membrane structure of HCC tissue and basement membrane breakthrough (23). MHCC97-H blank was set as the control group (Blank control; BC) and MHCC97-H gene interference was the negative control group (Native Contrast; NC), in which $G F P$ gene was transfected as marker gene into the two groups. The experimental groups comprised of the MHCC97H $T G F \beta_{1}$ gene interference and MHCC 97-H OPN gene interference groups, with both containing the GFP gene as reporter gene. MHCC97-H cells in log phase were harvested and dissociated with $0.25 \%$ Trypsin and $0.02 \%$ EDTA. Cells were counted under microscope and 24-well Transwell plates $(5.0 \mu \mathrm{m})$ were seeded in DMEM medium at densities of $5 \times 10^{4}$ cells/well in the upper chamber and $2 \times 10^{3}$ cells/well in the lower chamber. The plates were incubated at $37^{\circ} \mathrm{C}$ in a $5 \% \mathrm{CO}_{2}$ incubator. After $48 \mathrm{~h}$ of incubation, the wells were washed once with PBS and the cells were fixed with $40 \mathrm{~g} / 1$ paraformaldehyde for $10 \mathrm{~min}$ at $37^{\circ} \mathrm{C}$. The paraformaldehyde was then removed and the non-migrating cells in the upper chamber were wiped off with a cotton swab. The Transwell inserts were removed, inverted, air dried and rinsed twice with pre-cooled $\operatorname{PBS}\left(4^{\circ} \mathrm{C}\right)$ and fixed with pre-cooled $100 \%$ methanol $\left(4^{\circ} \mathrm{C}\right)$ for $10 \mathrm{~min}$. The methanol was removed, and the inserts were incubated for $10 \mathrm{~min}$ at room temperature in $200 \mu \mathrm{l}$ of $0.1 \%$ crystal violet (Abcam) that was added to the bottom of each well. Images of three randomly selected fields were taken using an inverted fluorescence microscope (x200; Olympus Corporation; MF53) and cell counts were performed.

MHCC97-H xenograft model. MHCC97-H cells in logarithmic growth phase were collected, centrifuged at 1,000 rpm for $5 \mathrm{~min}$ and the cell concentration was adjusted to $2.5 \times 10^{7}$ cells/ml to prepare a single cell suspension in DMEM medium. Nude mice were subcutaneously inoculated with $0.2 \mathrm{ml}$ cell suspension $\left(5 \times 10^{6}\right.$ cells/mouse $)$ of the corresponding group in the right side of the armpit. Light pressure was put on the injection site for $30 \mathrm{sec}$ following injection to prevent leakage of the cell suspension. Anesthesia was performed by intraperitoneal injection of $1 \%$ sodium pentobarbital. The dose for nude mice was $\sim 0.3 \mathrm{ml}$. The method of euthanasia was spinal dislocation.

BMSCs intervention in the MHCC97-H xenograft model and experimental methods. A total of 32 nude mice were randomly divided into four groups: MHCC97-H blank control (BC; $n=8)$, MHCC97-H-NC gene silencing negative control $(\mathrm{NC} ; \mathrm{n}=8)$, MHCC 97-H-OPN gene silencing $(\mathrm{n}=8)$ and MHCC $97-\mathrm{H}-T G F \beta_{I}$ gene silencing $(\mathrm{n}=8)$ groups. After the nude mice were inoculated for 14 days and tumor volume was allowed to grow to $\sim 50 \mathrm{~mm}^{3}$, prior to the initiation of the intratumoral injection of BMSCs ( $1 \times 10^{5}$ cells/tumor) biweekly for 4 weeks. Pathological observations of tumor tissue were performed using the HE staining method. Sample fixation: $95 \%$ ethanol fixation for $20 \mathrm{~min}$ and PBS wash twice, 1 min each time. Staining nucleus: Hematoxylin staining for 2-3 $\mathrm{min}$ and washing with water. 
Table I. TGF $\beta 1$ and OPN expression in MHCC97-H cells before and after siRNA $\left(2^{-\Delta \Delta C \mathrm{t}}\right)$.

Item Proliferation-related gene TGF $\beta 1$

Metastasis-associated gene OPN

MHCC97-H before gene interference

$1.000 \pm 0.026$

$1.000 \pm 0.135$

MHCC97-H after gene interference

$0.557 \pm 0.062$

$0.473 \pm 0.095$

TGF $\beta 1$, transforming growth factor $\beta 1$; OPN, osteopontin; MHCC97-H, MHCC97-H, high metastatic potential hepatocellular carcinoma.

Staining cytoplasm: Immerse in Eosin staining for $1 \mathrm{~min}$ and wash with water. The cells were then air dried and sealed with neutral gum. Observations were performed under a general optical microscope, magnification 200x.

Analysis of lung metastasis in MHCC97-H xenograft model. The lung metastasis animal model of MHCC97-H was performed according to a previous method (24). Briefly, cell lines in the logarithmic growth phase were collected, centrifuged at 1,000 rpm for $5 \mathrm{~min}$ and cell concentrations were adjusted to $2.5 \times 10^{7}$ cells $/ \mathrm{ml}$ to prepare a single cell suspension. Nude mice were intravenously inoculated via tail vein with $0.2 \mathrm{ml}\left(5 \times 10^{6}\right.$ cells/mouse) of prepared cell suspensions. Light pressure was applied to the injection site for $30 \mathrm{sec}$ after injection to prevent leakage of the cell suspension.

Analysis of MHCC97-H metastatic lung tumor pathology. The lungs were excised at the experimental end-point (14 day) and fixed in 4\% formaldehyde fixation for 3-5 days. The fixed tissues were processed through serial ethanol gradients $(50,70$, 80 and 95\%) and xylene, and then embedded in paraffin. The lungs were sectioned $(6 \mu \mathrm{m})$ and stained with DAPI for $10 \mathrm{~min}$ at $37^{\circ} \mathrm{C}$, followed by cover slipping with glycerol (cat. no. 228220 ; Shanghai Canspec Scientific Instruments Co., Ltd.) and PBS. HCC lung metastasis nodules were observed under a fluorescence microscope (magnification, 400). Differences in fluorescence intensity were analyzed using Image J software (v1.52; National Institutes of Health) and the integrated optical density (IOD) value was used as a semi-quantitative measurement index.

Analysis of expression of integrin $\alpha_{v} \beta_{3}$ in nude mice by immunofluorescence. The excised lung tissues underwent xylene dewaxing at $37^{\circ} \mathrm{C}$, gradient alcohol rehydration with xylene twice for $20 \mathrm{~min}$ each at room temperature, $100 \%$ ethanol twice for $5 \mathrm{~min}$ each, $95 \%$ ethanol for $5 \mathrm{~min}, 80 \%$ ethanol for $5 \mathrm{~min}$ and then washed three times with PBS for 3 min each at room temperature. Samples were rinsed with 0.001 M PBST (Beijing Solarbio Science and Technology Co., Ltd.) for $5 \mathrm{~min}, 3$ times, and blocked with $10 \%$ BSA (Thermo Fisher Scientific, Inc.) in a humidified chamber for $30 \mathrm{~min}$. Slides were placed in $0.01 \mathrm{M}$ citrate buffer $(\mathrm{pH}$ 6.0) in the microwave for $10 \mathrm{~min}$ and allowed to cool to room temperature, followed by three PBS rinses for $3 \mathrm{~min}$ for antigen retrieval. Primary antibodies were added to the slides in a dropwise manner and the slides were incubated at $4^{\circ} \mathrm{C}$ overnight. The slides were then washed three times for 3 min each with PBS. Secondary antibodies were added drop by drop and the slides were incubated at $37^{\circ} \mathrm{C}$ for $60 \mathrm{~min}$ and then rinsed three times with PBS for 5 min each. DAPI staining was performed at room temperature for $10 \mathrm{~min}$. The slides were cover

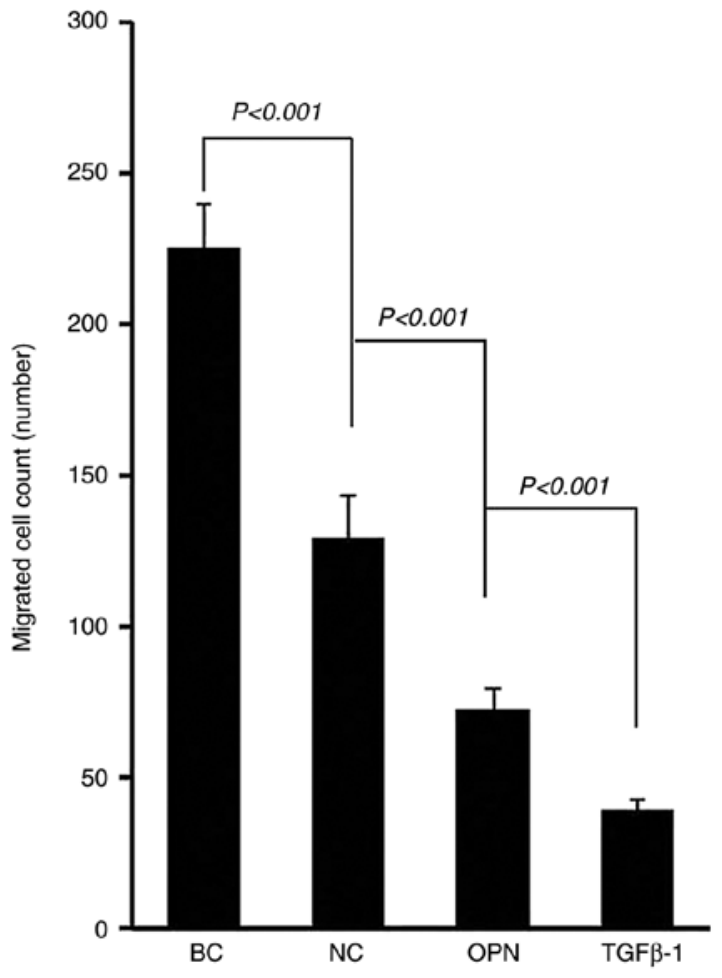

Figure 1. Histogram comparison of the migration of MHCC97-H cells before and after gene transfection. MHCC97-H, high metastatic potential hepatocellular carcinoma; $\mathrm{BC}$, blank control group; $\mathrm{NC}$, negative control group; OPN, osteopontin gene silencing group; TGF $\beta 1$, transforming growth factor $\beta 1$ gene silencing group.

slipped with glycerol and PBS, and observed using a confocal microscope (magnification, x150). Immunofluorescence exhibited a positive green expression. Quantitative analysis of integrin $\alpha_{\mathrm{v}} \beta_{3}$ expression by positive pixel levels in the metastatic hepatocellular carcinoma cells of lung tissue was analyzed with Image J software (v1.52; National Institutes of Health).

Analysis of animal model test index. Each group of nude mice was weighed 1 week following cell inoculation and tumor volume was measured. Three times a week, the longest diameter (a) and the shortest diameter (b) of the tumor were measured with Vernier calipers and tumor volume (V) was calculated: $\mathrm{V}\left(\mathrm{cm}^{3}\right)=1 / 2 \mathrm{ab}^{2}=0.5 \mathrm{ab}^{2}$, and a tumor growth curve was plotted. Furthermore, the animals were weighed three times a week, and the animal tumor weight was calculated as: total animal weight - tumor volume (assuming a tumor density of 1). The following calculations were used for analysis: tumor volume inhibition rate $(\%)=(1$-average tumor volume in experimental group/mean tumor volume in control group) 
Table II. Comparison of tumor volume and weight in hepatocellular carcinoma animal models following 28 days of BMSC cell intervention.

\begin{tabular}{lcr}
\hline Group & Tumor volume $\left(\mathrm{mm}^{3}\right)$ & Tumor weight $(\mathrm{g})$ \\
\hline MHCC97-H BC & $3064.90 \pm 821.78^{\mathrm{a}, \mathrm{b}}$ & $20.52 \pm 3.32$ \\
MHCC97-H NC & $2776.62 \pm 704.36^{\mathrm{a}, \mathrm{b}}$ & $18.90 \pm 1.87$ \\
MHCC97-H OPN & $1200.25 \pm 181.59^{\mathrm{a}}$ & $23.72 \pm 2.53$ \\
MHCC97-H TGFß1 & $595.83 \pm 343.83$ & $23.34 \pm 2.23$ \\
\hline
\end{tabular}

Data are presented as mean $\pm \mathrm{SD}$. ${ }^{\mathrm{a}} \mathrm{P}<0.01$ vs. the TGF $\beta 1$ gene silence group. ${ }^{\mathrm{b}} \mathrm{P}<0.05$ vs. the $\mathrm{OPN}$ gene silence group. BMSC, bone marrow mesenchymal stem cell; MHCC97-H blank control group; NC, negative control group; OPN, OPN gene interference group; TGF $\beta 1$, TGF $\beta 1$ gene interference group.

$\mathrm{x} 100 \%$; tumor weight inhibition rate $(\%)=(1$-average tumor weight in experimental group/mean tumor weight in control group) $\mathrm{x} 100 \%$.

Statistical analysis. Experimental data are expressed as mean \pm SD. The data were analyzed using SPSS statistical software (v16.0; IBM Corp.). The IOD value quantitative comparison between cell counts was performed using one-way ANOVAs with post-hoc LSD tests, and $\mathrm{P}<0.05$ was considered to indicate a statistically significant difference.

\section{Results}

$T G F \beta_{1}$ and $O P N$ expression differences before and after gene silencing in $\mathrm{MHCC} 97-\mathrm{H}$ cells. The relative quantitative results are shown in Table I. $O P N$ and $T G F \beta_{1}$ expression were clearly decreased in the MHCC97-H cells following gene silencing.

Cell counts from Transwell assay experiments on MHCC97-H cells. The results demonstrated that there was a significant difference between the control group compared with the other groups in the number of migrated cells (Fig. 1; F=7.461; $\mathrm{P}<0.001)$. This indicated that the number of migrating cells following gene interference was significantly reduced, particularly in the MHCC97-H OPN and MHCC97-H TGF $\beta_{1}$ interference groups $(\mathrm{P}<0.001)$.

BMSC intervention in the MHCC97-H animal model. After the nude mice were inoculated for 14 days and the tumor volume was $>50 \mathrm{~mm}^{3}$, the intratumoral injection of human BMSCs was initiated for intervention. The BMSC intervention groups are shown in Table II. At the end of the experiment, each group of mice was sacrificed and tumors were excised. It was found that the boundary between tumors and surrounding tissues was clear, with slight adhesion between the skin and subcutaneous connective tissue for all mice bearing-tumor. Additionally, capsules were intact.

Comparison of the tumor volumes revealed that the MHCC97-H gene-silenced group had statistically significantly smaller compared with the $\mathrm{BC}$ group $(\mathrm{P}<0.05)$, indicating that BMSCs had a significant inhibitory effect on tumor volume
Table III. Analysis of the inhibition rate of hepatocellular carcinoma before and after gene modification in animal models.

\begin{tabular}{lcc}
\hline Group & $\begin{array}{c}\text { Tumor volume } \\
\text { inhibition rate (\%) }\end{array}$ & $\begin{array}{c}\text { Tumor weight } \\
\text { inhibition rate (\%) }\end{array}$ \\
\hline MHCC97-H BC & 0.00 & 0.00 \\
MHCC97-H NC & 9.41 & 4.99 \\
MHCC97-H OPN & 60.84 & 47.23 \\
MHCC97-H TGF $\beta 1$ & 80.56 & 84.08 \\
\hline
\end{tabular}

BC, blank control group; NC, negative control group; OPN, OPN gene interference group; TGF $\beta 1$, TGF $\beta 1$ gene interference group.

in the gene-silenced group. Comparison of tumor weights demonstrated that BMSCs had no significant inhibitory effect on tumor weight following gene silencing in the MHCC97-H tumor model.

MHCC97-H tissue inhibition rate was calculated using the inhibition rates of tumor volume inhibition and tumor weight. The results are shown in Table III. BMSCs had mild inhibitory effects on the tumor volume and tumor weight in the MHCC97-H NC group compared with the MHCC97-H BC group. Compared with the MHCC97-H BC and NC groups, BMSCs had a significant inhibitory effect on both tumor volume and tumor weight in the MHCC97-H OPN-silenced (volume inhibition rate $60.84 \%$, weight inhibition rate $47.23 \%$ ) and MHCC97-H TGF $\beta_{1}$-silenced groups (volume inhibition rate $80.56 \%$, weight inhibition rate $84.08 \%$ ).

Pathological results of BMSC intervention in $\mathrm{MHCC} 97-\mathrm{H}$ xenograft model before and after gene modification. Increased tumor necrosis was observed in the MHCC97-H BC and MHCC97-H NC groups compared to the MHCC97-H group with $O P N$ and $T G F \beta 1$ genes silenced groups (Fig. 2). Fibroproliferation was evident and there was an increased number of mitoses in all groups. Furthermore, there was relatively less fibrosis and mitoses in the MHCC97-H $O P N$-silencing group, while the MHCC97-H TGF $\beta 1$-silenced 

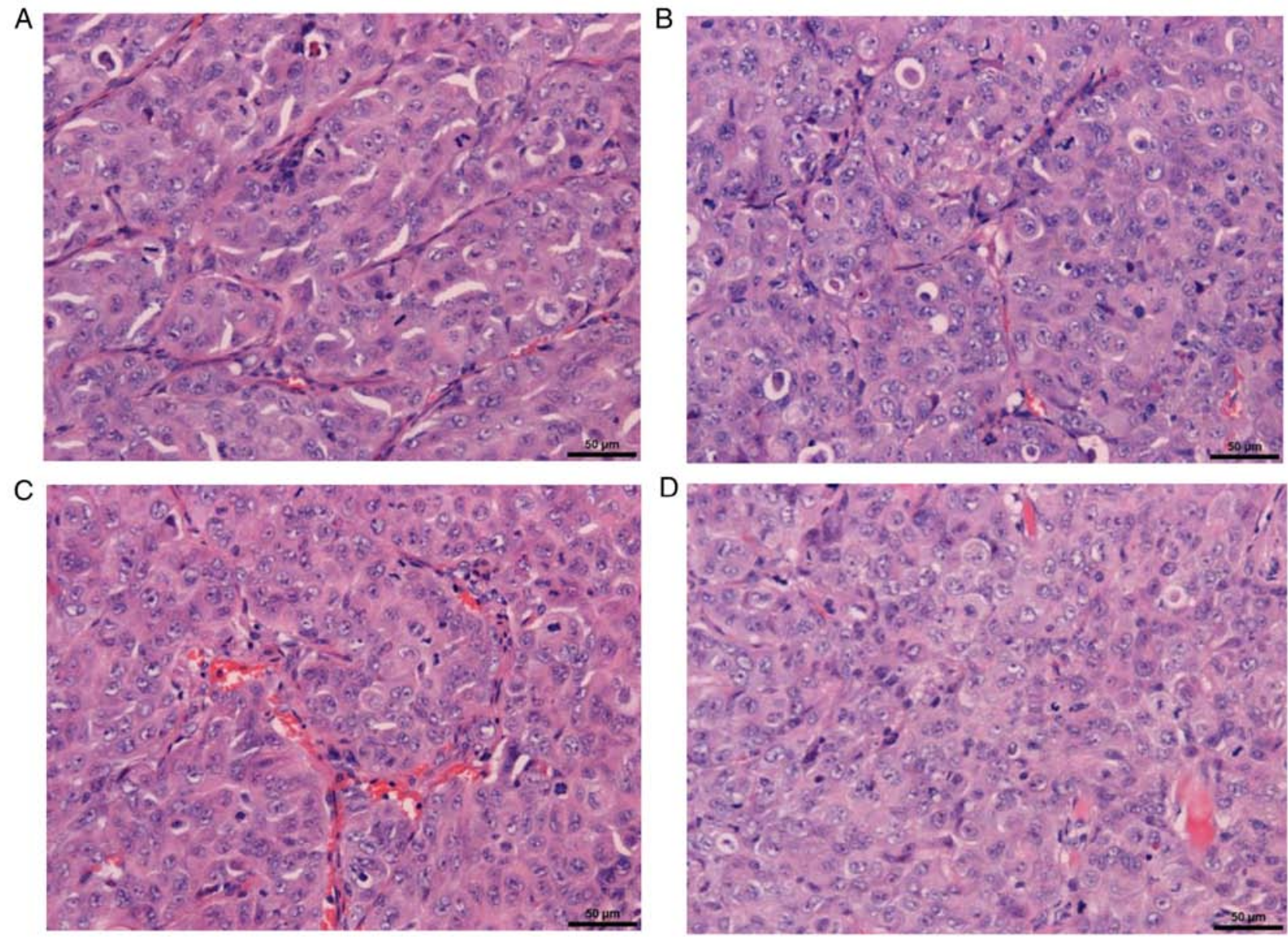

Figure 2. The pathological results of hepatocellular carcinoma before and after gene silencing by bone marrow mesenchymal stem cells (H\&E staining; magnification, x200). (A) MHCC97-H blank control group; (B) MHCC97-H gene silencing negative control group; (C) MHCC97-H OPN-silenced group; (D) MHCC97-H TGF $\beta 1$-silenced group. OPN, osteopontin; TGF $\beta 1$, transforming growth factor $\beta 1$.

group exhibited significantly more fibrosis and mitoses, when compared with the control group.

Lung metastasis animal model fluorescence imaging results of $M H C C 97-H$. The results demonstrated that there were more tumor cells in the lung tissues of the $\mathrm{BC}$ and $\mathrm{NC}$ groups (Fig. 3A and B). There were fewer tumor cells in the $O P N$ - and $T G F \beta_{1}$-silenced groups in the lung tissue compared with the BC group (Fig. 3C and D), indicating that the lung metastasis of gene-silenced MHCC97-H tumor potentially declined.

To further analyze the metastasis of HCC cells in lung tissue, quantitative analysis was performed on the fluorescence intensity of MHCC97-H in pathological sections using Image $\mathbf{J}$ software. IOD was used as a quantitative indicator (Fig. 3E). The IOD values of the MHCC97-H cells were lower in the $O P N$ - and $T G F \beta_{l}$-silenced groups compared with the $\mathrm{BC}$ and $\mathrm{NC}$ groups. This difference was statistically significant $(\mathrm{P}<0.05)$, indicating that the lung metastasis ability of MHCC 97-H was reduced following interference by $O P N$ and $T G F \beta_{1}$ genes, which was consistent with the results observed using a microscope.

Immunofluorescence of metastasis-associated integrin $\alpha_{v} \beta_{3}$ expression. The positive staining for integrin $\alpha_{v} \beta_{3}$ demonstrated a strong green color (Fig. 4A-C). The density of green fluorescent MHCC97-H cells was significantly reduced in the gene interference groups compared with the control group. The fluorescence intensity of integrin $\alpha_{v} \beta_{3}$ expressed in MHCC97-H cells in the lung was quantitatively analyzed using Image $\mathbf{J}$ software (Fig. 4D). The results demonstrated that the IOD value of migrated cells was not statistically different among the three groups $(\mathrm{P}>0.05)$, indicating that neither $O P N$ nor $T G F \beta_{l}$ gene interference in MHCC97-H altered the ability of the cells to express integrin $\alpha_{v} \beta_{3}$.

\section{Discussion}

In the present study, two genes were silenced in MHCC97-H cells. OPN is a type of secreted phosphorylated glycoprotein and its molecular structure contains an RGD (Arg-Gly-Asp) polypeptide sequence. By combining with integrin $\alpha_{v} \beta_{3}$ or CD44, OPN participates in important biological processes, such as cell adhesion and signal transduction. Furthermore, it promotes tumor cell metastasis (25). A previous study demonstrated that OPN is significantly overexpressed in MHCC97-H cells, suggesting that OPN is involved in the metastatic behavior of HCC (26). Furthermore, the metastatic behavior of HCC can be delayed by blocking the expression of OPN (27).

TGF $\beta_{1}$ is an important biological factor involved in tumor growth, invasion and metastasis, and in the occurrence and 
A

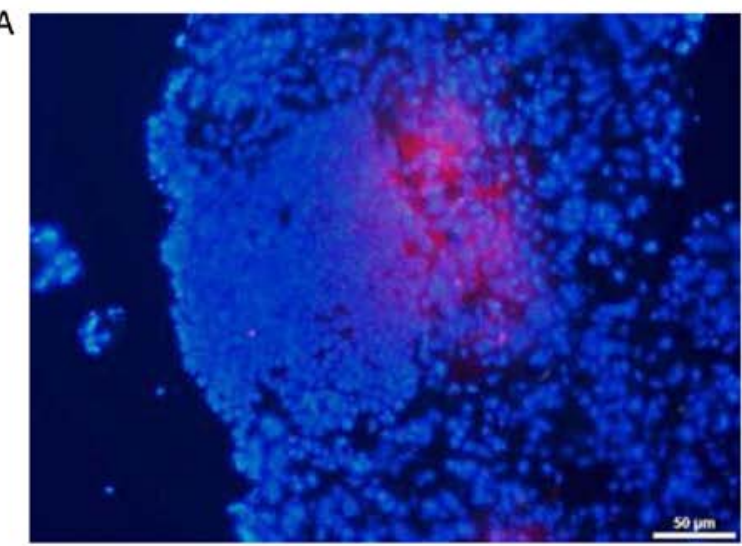

C
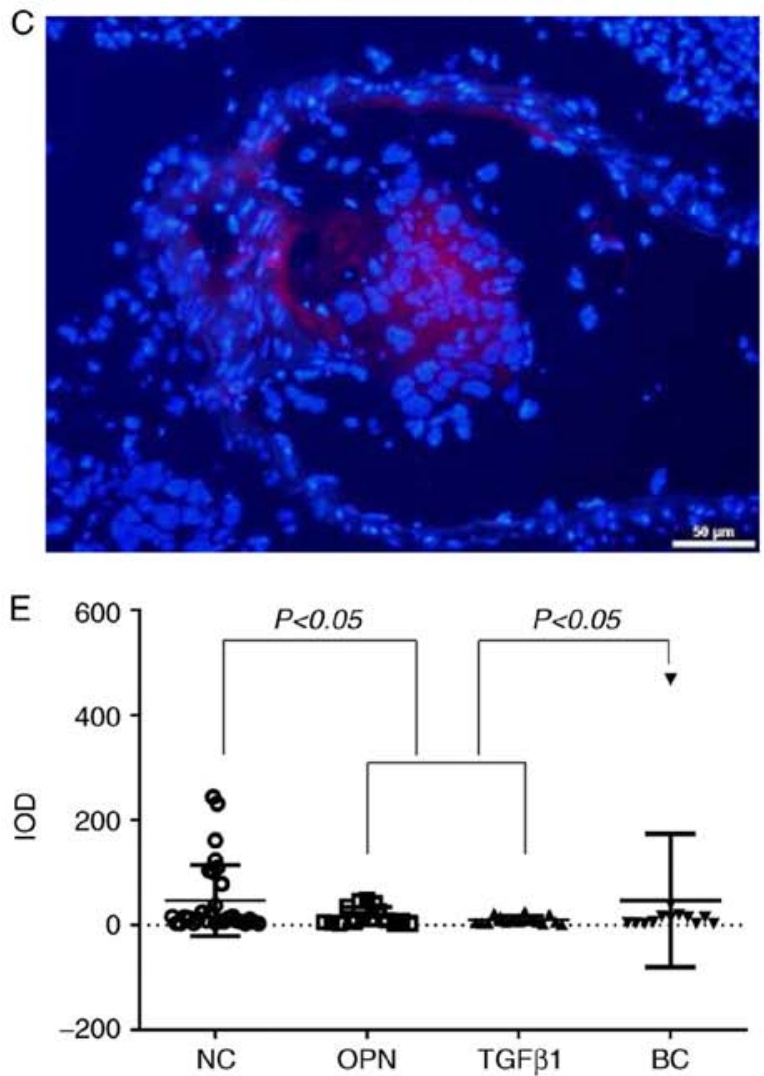
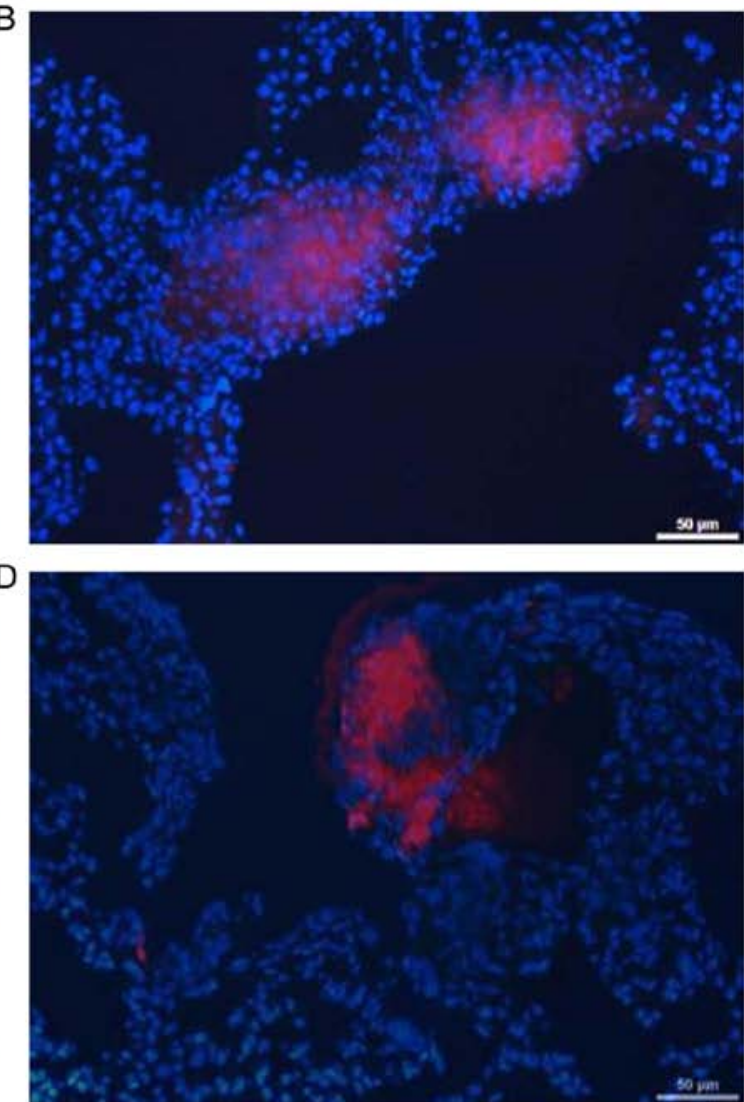

Figure 3. Fluorescence imaging of the MHCC97-H tumor lung metastasis animal model. The tumor cells are red and the nuclei of the lungs are blue. Magnification, x200. (A) Blank control group, (B) gene-negative control group, (C) TGF $\beta 1$ interference group, (D) OPN interference group, and (E) quantitative analysis of fluorescence imaging of metastatic hepatocellular carcinoma cells in lung tissue. MHCC97-H, high metastatic potential hepatocellular carcinoma; IOD, integrated optical density; NC, negative control group; OPN, osteopontin gene silencing group; TGF $\beta 1$, transforming growth factor $\beta 1$ gene silencing group

progression of $\mathrm{HCC}$ in terms of proliferation and metastasis (28). TGF $\beta_{1}$ and integrin $\alpha_{\mathrm{v}} \beta_{3}$ receptors are associated with tumor metastasis-related signaling pathways (29). Integrin and $\mathrm{TGF} \beta_{1}$ receptor-mediated signal transduction pathways share certain signaling molecules, such as Rac1 and ERK, and interact to exert a variety of biological effects, such as cell collagen hyperplasia and cell fibrogenesis (30). Therefore, based on previous studies, the current study silenced $O P N$ and $T G F \beta_{1}$ genes in MHCC97-H. Changes in metastasis and proliferation ability in MHCC97-H cells were observed following BMSC treatment in vitro and in vivo. The Transwell method was used to evaluate the metastatic ability at the cellular level, as it simulates the basement membrane structure of HCC tissue and basement membrane breakthrough, which is a critical step in metastasis (25). Animal models were used to evaluate metastatic ability in a lung metastasis model of MHCC97-H. MHCC97-H cells were injected before and after gene interference in order to increase the concentrations of BMSCs in tumors and the lung metastasis of HCC was observed after 28 days.

The results of the cytology experiments and the animal model indicated that BMSCs migration ability following gene silencing in MHCC97-H cells was significantly decreased, especially following $T G F \beta_{1}$ silencing. This indicated that biological factors associated with OPN and TGF $\beta 1$ were involved in HCC metastasis. Furthermore, the 
A

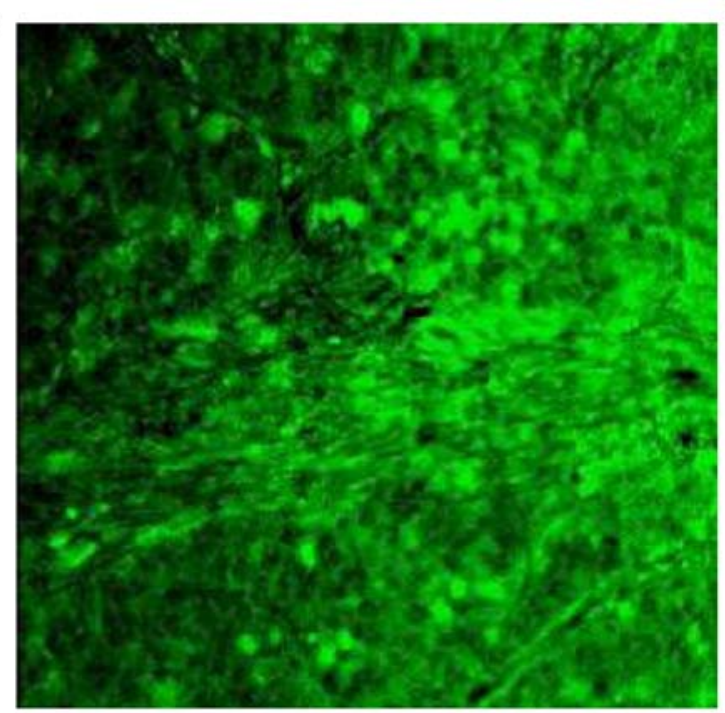

C

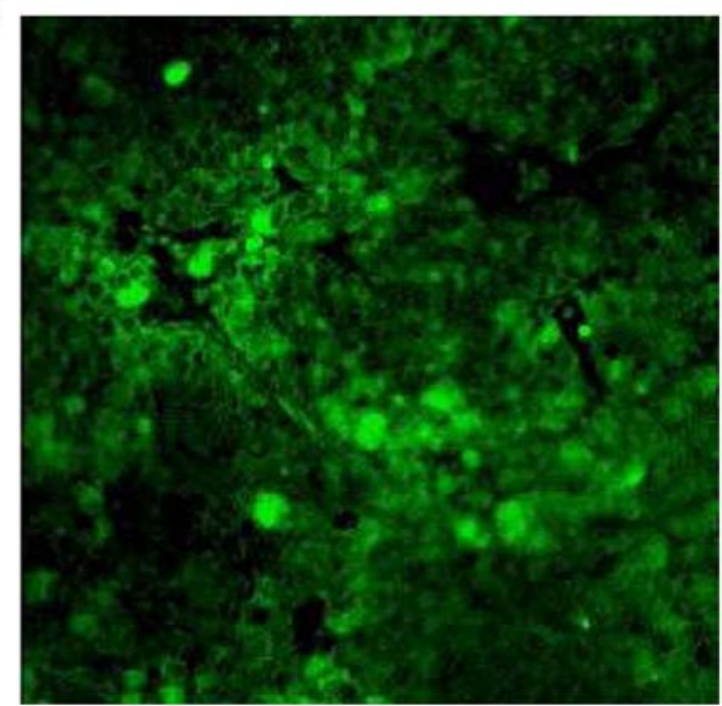

B

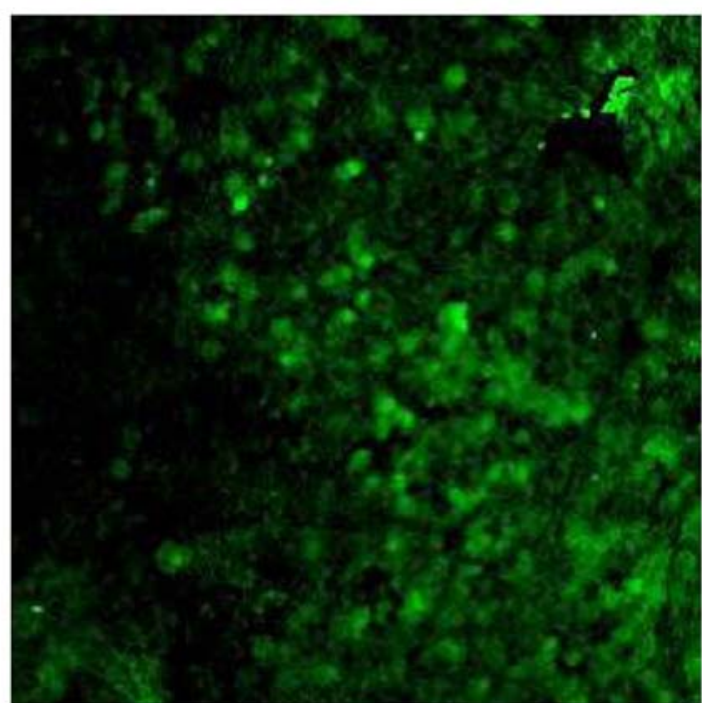

D

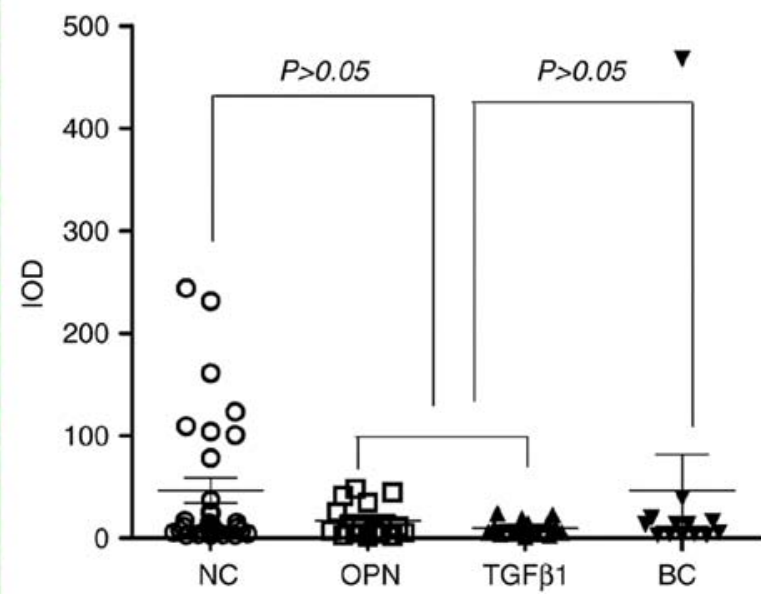

Figure 4. Expression of integrin $\alpha_{\mathrm{v}} \beta_{3}$ in gene-silenced MHCC97-H animal model. Magnification, x200. (A) Negative control group, (B) OPN-silenced group, and (C) TGF $\beta 1$-silenced group. (D) Quantitative analysis of integrin $\alpha_{\mathrm{v}} \beta_{3}$ expression in hepatocellular carcinoma cells in lung tissue. IOD, integrated optical density; NC, negative control group; OPN, osteopontin gene silencing group; TGF $\beta 1$, transforming growth factor $\beta 1$ gene silencing group.

results suggested that BMSCs are more effective at reducing metastasis in gene-silenced MHCC97-H cells. Therefore, the $T G F \beta_{1}$ gene may be the best target for BMSCs to interfere with metastatic behavior in HCC. Previous studies $(31,32)$ have demonstrated that $T G F \beta_{1}$ overexpression may lead to excessive suppression of immune cells, including $\mathrm{T}$ and $\mathrm{B}$ lymphocytes, by reducing the immune surveillance function of the host, immune response and clearance to invading pathogens and by increasing tumor cell elimination, leading to the occurrence and metastasis of tumors. This mechanism may explain the reason $T G F \beta_{1}$ gene silencing is more conducive to inhibiting the metastasis of HCC. Further previous studies have demonstrated that low doses of TGF $\beta_{1}(\leq 0.25 \mathrm{ng} / \mathrm{ml})$ increases BMSC proliferation, while higher doses of TGF $\beta 1$ ( $\geq 1 \mathrm{ng} / \mathrm{ml})$ inhibit their proliferation (33). Additionally, there are data that indicate that low doses of TGF $\beta$ signaling alongside BMSCs may lower their immunomodulatory potential (34). Therefore, with low TGF $\beta_{1}$ expression in HCC, BMSCs may be better at inhibiting the proliferation and metastasis of HCC.
The results for tumor weight and volume indicated that BMSCs have a positive effect on the inhibition of HCC tissues growth after gene silencing. The lack of significant change in tumor weight may be explained by the pathological results, as tumor necrosis and fibrosis increased, and number of mitoses decreased in the experimental groups compared with the control group. Therefore, the reason that the tumor weight did not change significantly was associated with the increase in fibrous tissue in tumors with necrotic components. Furthermore, solid tumor weight inhibition ratios were different from tumor weight measurements. When the tumor inhibition rate was calculated, the weight of the animal itself was taken into account. Because of excessive nutrient consumption of tumor-bearing nude mice, the total weight of the animals reduced (35). However, changes in tumor volume inhibition were consistent with the trend of simply measuring volume changes. Moreover, $O P N$ silencing promoted cell apoptosis, delayed tumor cell proliferation and promoted fibrous tissue proliferation, a result that is consistent with that of Zhu et al (36). Following $T G F \beta_{1}$ silencing, the promotion of 
tumor cell proliferation was weakened and replaced by fibrous tissue proliferation, which was consistent with the function of $T G F \beta_{I}$ reported in the literature (37). The ability of metastasis and proliferation of gene-silenced MHCC97-H cells and animal models following BMSC intervention was markedly reduced. These data were confirmed by the lung metastasis fluorescence imaging in the MHCC97-H animal model.

In order to further explore the metastatic potential changes in gene-silenced MHCC97-H, the expression of the key biological molecule integrin $\alpha_{\mathrm{v}} \beta_{3}$ in HCC tissue with lung metastasis was analyzed. However, the experimental results revealed no significant changes in the expression of integrin $\alpha_{\mathrm{v}} \beta_{3}$ in MHCC97-H cells in the lungs of the $O P N$ -

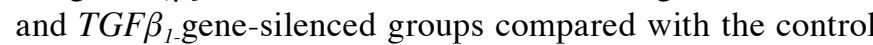
group. This may be related to the expression of integrin $\alpha_{v} \beta_{3}$. The vascular endothelium, as well as the cancer tissue, is also involved in the expression of integrin $\alpha_{v} \beta_{3}$ (38). Thus, the decrease in metastatic potential following gene silencing in MHCC97-H was not associated with integrin $\alpha_{v} \beta_{3}$ expression, but was related to the decrease in OPN and TGF $\beta_{1}$ expression. At lower levels, OPN and TGF $\beta_{1}$ do not bind to integrin $\alpha_{\mathrm{v}} \beta_{3}$ (39). Therefore, it is possible that low OPN and TGF $\beta_{1}$ expression in MHCC97-H may reduce metastasis by other mechanisms. Previous findings have suggested that OPN promotes tumor proliferation and metastasis by mediating TGF $\beta_{1}$-dependent mesenchymal stem cell-to-fibrocyte transformation mechanisms (40). Another previous study investigated the relationship between TGF $\beta_{1}$ and $\mathrm{MHCC} 97-\mathrm{H}$ metastasis and the results demonstrated that high TGF $\beta$ RII expression may inhibit the proliferation, migration and invasion of MHCC97-H (41).

BMSCs have different efficacies for HCC interventions, such as influencing tumor progression, and these differences may be related to the tumor microenvironment (13). Numerous factors may be involved in BMSC intervention in tumors. MCP-3 can increase the migration of liver cancer cells with different metastatic potential and StTRAIL can promote apoptosis of liver cancer cells $(42,43)$. In the present study, TGF $\beta_{1}$ and OPN were involved in the proliferation and metastasis of tumors. The results of the current study indicated that the efficacy of BMSCs intervention in MHCC97-H following gene silencing was significantly increased compared with the experimental control group.

In conclusion, the current study employed gene silencing methods and the results revealed that the reduction of $O P N$ and $T G F \beta_{1}$ expression led to reduced metastatic potential in MHCC97-H. The metastatic potential and proliferative potential of MHCC97-H following BMSC intervention were significantly reduced both in vitro and in vivo, particularly in the $T G F \beta_{1}$-silenced group. The reduced metastatic potential following gene silencing in MHCC97-H was not related to integrin $\alpha_{\mathrm{v}} \beta_{3}$ expression. Therefore, OPN and TGF $\beta_{1}$ factors may be considered to be targets for BMSC intervention, of which $\mathrm{TGF} \beta_{1}$ may be the best targets. Since the regulation mechanism of MHCC97-H metastatic potential was not further studied, research into stem cells in metastasis mechanisms in $\mathrm{HCC}$ is necessary. The current study provides a basis for treatment of HCC using BMSCs. Future research should involve searching for a suitable gene that inhibits the metastasis and proliferation of HCC.

\section{Acknowledgements}

Not applicable.

\section{Funding}

The present study was supported by Chinese National Natural Science Foundation (grant no. 81271607).

\section{Availability of data and materials}

The datasets used and/or analyzed during the present study are available from the corresponding author on reasonable request.

\section{Authors' contributions}

TL designed the experimental trial, acquired and analyzed the data, and drafted the manuscript. BZ designed the clinical trial, collected experimental data and analyzed the data. LS and YZ acquired data and drafted the manuscript. YF contributed to the conception and design, administrative support. All authors read and approved the final manuscript.

\section{Ethics approval and consent to participate}

Animal experiments were approved by the Ethics Committee of the Fourth Medical Center of the Chinese PLA General Hospital.

\section{Patient consent for publication}

Not applicable.

\section{Competing interests}

The authors declare that they have no competing interests.

\section{References}

1. Zhao P, Dai M, Chen W and Li N: Cancer trends in China. Jpn J Clin Oncol 40: 281-285, 2010.

2. Ni J and Hua HQ: Progress in the treatment of primary hepatocellular carcinoma by sorafenib combined with traditional Chinese medicine. Mil Med J Southeast China 17: 175-177, 2015.

3. Han TS, Ban HS, Hur K and Cho HS: The epigenetic regulation of HCC metastasis. Int J Mol Sci 19: 3978, 2018.

4. Li Y, Tang ZY, Ye SL, Liu YK, Chen J, Xue Q, Chen J, Gao DM and Bao WH: Establishment of cell clones with different metastatic potential from the metastatic hepatocellular carcinoma cell line MHCC97. World J Gastroenterol 7: 630-636, 2001.

5. Li Y, Tang Y, Ye L, Liu B, Liu K, Chen J and Xue Q: Establishment of a hepatocellular carcinoma cell line with unique metastatic characteristics through in vivo selection and screening for metastasis-related genes through cDNA microarray. J Cancer Res Clin Oncol 129: 43-51, 2003.

6. Li GC, Ye QH, Dong QZ, Ren N, Jia HL and Qin LX: TGF beta1 and related-Smads contribute to pulmonary metastasis of hepatocellular carcinoma in mice model. J Exp Clin Cancer Res 31: 93, 2012.

7. Batlle E and Clevers H: Cancer stem cells revisited. Nat Med 23: 1124-1134, 2017.

8. Liu WH, Song FQ, Ren LN, Guo WQ, Wang T, Feng YX, Tang LJ and Li K: The multiple functional roles of mesenchymal stem cells in participating in treating liver diseases. J Cell Mol Med 19: 511-520, 2015. 
9. Vakhshiteh F, Atyabi F and Ostad SN: Mesenchymal stem cell exosomes: A two-edged sword in cancer therapy. Int J Nanomedicine 14: 2847-2859, 2019.

10. Tsuchiya A, Takeuchi S, Watanabe T, Yoshida T, Nojiri S, Ogawa $\mathrm{M}$ and Terai $\mathrm{S}$ : Mesenchymal stem cell therapies for liver cirrhosis: MSCs as 'conducting cells' for improvement of liver fibrosis and regeneration. Inflamm Regen 39: 18, 2019.

11. Guo XZ, Liu X, Wang D, Zhao JJ, Li YH, Shao XD and Ren LN: The effect of autologous bone marrow stem cell transplantation on liver cirrhosis with different causes. Chin J Digestion 31 : 53-54, 2011.

12. Vainshtein JM, Kabarriti R, Mehta KJ, Roy-Chowdhury J and Guha C: Bone marrow-derived stromal cell therapy in cirrhosis: Clinical evidence, cellular mechanisms, and implications for the treatment of hepatocellular carcinoma. Int J Radiat Oncol Biol Phys 89: 786-803, 2014.

13. Yin Z, Jiang K, Li R, Dong C, Wang L and Wang L: Multipotent mesenchymal stromal cells play critical roles in hepatocellular carcinoma initiation, progression and therapy. Mol Cancer 17: $178,2018$.

14. Liu Y, Ren H, Zhou Y, Shang L, Zhang Y, Yang F and Shi X The hypoxia conditioned mesenchymal stem cells promote hepatocellular carcinoma progression through YAP mediated lipogenesis reprogramming. J Exp Clin Cancer Res 38: 228, 2019

15. Li TR, Cai LJ, Zhao SH, Wei ZM, Huo TL, Lu GM and Song B Effect of OPN transfected BMSCs on MHCC97-H. Chin J Gastroenterol Hepatol 24: 1057-1061, 2015.

16. Li GC, Ye QH, Xue YH, Sun HJ, Zhou HJ, Ren N, Jia HL, Shi J, Wu JC, Dai C, et al: Human mesenchymal stem cells inhibit metastasis of a hepatocellular carcinoma model using the MHCC97-H cell line. Cancer Sci 101: 2546-2553, 2010.

17. Li TR, Du XK, Song B, Ye YK, Wei ZM and Huo TL: Experimental study of TGF $\beta 1$ transfected hMSC intervene MHCC97-H. Chin J Gastroenterol Hepatol 22: 615-619, 2013.

18. Li GC, Zhang HW, Zhao QC, Sun LI, Yang JJ, Hong L, Feng F and Cai L: Mesenchymal stem cells promote tumor angiogenesis via the action of transforming growth factor $\beta$. Oncol Lett 11: 1089-1094, 2016

19. Zhang R, Pan X, Huang Z, Weber GF and Zhang G: Osteopontin enhances the expression and activity of MMP-2 via the SDF-1/ CXCR4 axis in hepatocellular carcinoma cell lines. PLoS One 6: e23831, 2011

20. Weber CE, Kothari AN, Wai PY, Li NY, Driver J, Zapf MA, Franzen CA, Gupta GN, Osipo C, Zlobin A, et al: Osteopontin mediates an MZF1-TGF- $\beta$ 1-dependent transformation of mesenchymal stem cells into cancer-associated fibroblasts in breast cancer. Oncogene 34: 4821-4833, 2015.

21. General Administration of Quality Supervision, Inspection and Quarantine of the People's Republic of China,and Standardization Administration of the People's Republic of China: Laboratory animals-Nutrients for formula feeds (GB 14924.3-2010) issued by National Standards of People's Republic of China, December 23, 2010. http://www.gb688.cn/bzgk/gb

22. Livak KJ and Schmittgen TD: Analysis of relative gene expression data using real-time quantitative PCR and the 2(-Delta Delta C(T)) Method. Methods 25: 402-408, 2001.

23. Marshall J: Transwell ${ }^{\circledR}$ invasion assays. Methods Mol Biol 769: 97-110, 2011.

24. Kang Y: Imaging TGF $\beta$ signaling in mouse models of cancer metastasis. Methods Mol Biol 1344: 219-232, 2016.

25. Icer MA and Gezmen-Karadag M: The multiple functions and mechanisms of osteopontin. Clin Biochem 59: 17-24, 2018.

26. Ye QH, Qin LX, Forgues M, He P, Kim JW, Peng AC, Simon R, Li Y, Robles AI, Chen Y, et al: Predicting hepatitis $B$ virus-positive metastatic hepatocellular carcinomas using gene expression profiling and supervised machine learning. Nat Med 9: 416-423, 2003.

27. Huang H, Zhang XF, Zhou HJ, Xue YH, Dong QZ, Ye QH and Qin LX: Expression and prognostic significance of osteopontin and caspase-3 in hepatocellular carcinoma patients after curative resection. Cancer Sci 101: 1314-1319, 2010.
28. Budhu A and Wang XW: The role of cytokines in hepatocellular carcinoma. J Leukoc Biol 80: 1197-1213, 2006.

29. Tang J, Gifford CC, Samarakoon R and Higgins PJ: Deregulation of negative controls on TGF- $\beta 1$ signaling in tumor progression. Cancers (Basel) 10: 159, 2018.

30. Hayashida T, Jones JC, Lee CK and Schnaper HW: Loss of beta1-integrin enhances TGF-beta1-induced collagen expression in epithelial cells via increased alphavbeta3-integrin and Rac1 activity. J Biol Chem 285: 30741-30751, 2010.

31. Li MO, Wan YY, Sanjabi S, Robertson AK and Flavell RA: Transforming growth factor-beta regulation of immune responses. Annu Rev Immunol 24: 99-146, 2006.

32. Prasad P, Tiwari AK, Kumar KM, Ammini AC, Gupta A, Gupta R and Thelma BK: Association of TGFbeta1, TNFalpha, CCR 2 and CCR 5 gene polymorphisms in type-2 diabetes and renal insufficiency among Asian Indians. BMC Med Genet 8: 20 , 2007.

33. Li D, Liu Q, Qi L, Dai X, Liu H and Wang Y: Low levels of TGF- $\beta 1$ enhance human umbilical cord-derived mesenchymal stem cell fibronectin production and extend survival time in a rat model of lipopolysaccharide-induced acute lung injury. Mol Med Rep 14: 1681-1692, 2016.

34. de Araújo Farias V, Carrillo-Gálveza AB, Martína F and Andersona P: TGF- $\beta$ and mesenchymal stromal cells in regenerative medicine, autoimmunity and cancer. Cytokine Growth Factor Rev 43: 25-37, 2018.

35. Molfino A, Amabile MI and Muscaritoli M: Nutrition support for treating cancer-associated weight loss: An update. Curr Opin Support Palliat Care 12: 434-438, 2018

36. Zhu Y, Gao XM, Yang J, Xu D, Zhang Y, Lu M, Zhang Z, Sheng YY, Li JH, Yu XX, et al: C-C chemokine receptor type 1 mediates osteopontin-promoted metastasis in hepatocellular carcinoma. Cancer Sci 109: 710-723, 2018.

37. Neuzillet C, de Gramont A, Tijeras-Raballand A, de Mestier L, Cros J, Faivre S and Raymond E: Perspectives of TGF- $\beta$ inhibition in pancreatic and hepatocellular carcinomas. Oncotarget 5: 78-94, 2014.

38. Zhou JP and Zhou WP: Expression of VEGF, integrin $\alpha \mathrm{V}$ and MVD in viable residual tumor tissues from large hepatocellular carcinoma after TACE. Mil Med J Southeast China 12: 206-208, 2010.

39. Li TR, Yu MH, Huang XB, Yang ZJ, Lu GM and Li YJ: Magnetic resonance Gd-RGD imaging study of hepatocellular carcinoma with high and low metastatic potential before and after human bone marrow-derived mesenchymal stem cell intervention. Chin Med J (Engl) 130: 2591-2600, 2017.

40. HayashidaT,WuMH,PierceA,Poncelet AC,Varga JandSchnaperHW: MAP-kinase activity necessary for TGFbetal-stimulated mesangial cell type I collagen expression requires adhesion-dependent phosphorylation of FAK tyrosine 397. J Cell Sci 120: 4230-4240, 2007.

41. Li Y, Liu G, Li X, Dong H, Xiao W and Lu S: Long non-coding RNA SBF2-AS1 promotes hepatocellular carcinoma progression through regulation of miR-140-5p-TGFBR1 pathway. Biochem Biophys Res Commun 503: 2826-2832, 2018

42. Wen X, Yao M, Lu Y, Chen J, Zhou J, Chen X, Zhang Y, Lu W, Qian X, Zhao J, et al: Integration of prealbumin into child-pugh classification improves prognosis predicting accuracy in HCC patients considering curative surgery. J Clin Transl Hepatol 6: 377-384, 2018

43. Deng Q, Zhang Z, Feng X, Li T, Liu N, Lai J, Shuai L, Xiong Q, Fu C, Zou H, et al: TRAIL-secreting mesenchymal stem cells promote apoptosis in heat-shock-treated liver cancer cells and inhibit tumor growth in nude mice. Gene Ther 21: 317-327, 2014.

This work is licensed under a Creative Commons Attribution-NonCommercial-NoDerivatives 4.0 International (CC BY-NC-ND 4.0) License. 